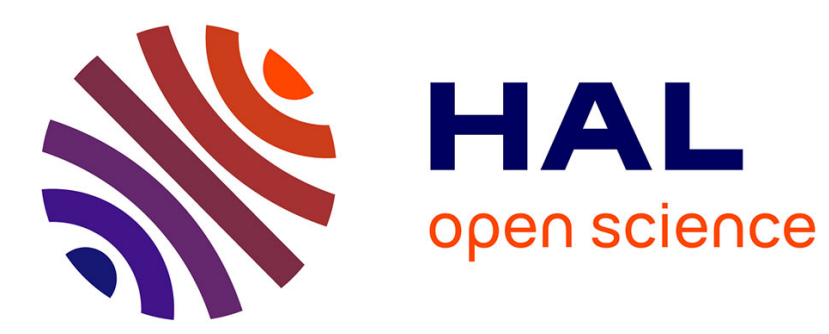

\title{
Erratum - Capillary rise of a wetting fluid in a semi-circular groove
}

Elie Raphaël

\section{To cite this version:}

Elie Raphaël. Erratum - Capillary rise of a wetting fluid in a semi-circular groove. Journal de Physique, 1989, 50 (9), pp.1135-1135. 10.1051/jphys:019890050090113500 . jpa-00210982

\section{HAL Id: jpa-00210982 https://hal.science/jpa-00210982}

Submitted on 1 Jan 1989

HAL is a multi-disciplinary open access archive for the deposit and dissemination of scientific research documents, whether they are published or not. The documents may come from teaching and research institutions in France or abroad, or from public or private research centers.
L'archive ouverte pluridisciplinaire HAL, est destinée au dépôt et à la diffusion de documents scientifiques de niveau recherche, publiés ou non, émanant des établissements d'enseignement et de recherche français ou étrangers, des laboratoires publics ou privés. 


\section{Erratum}

Capillary rise of a wetting fluid in a semi-circular groove

\section{Elie Raphaël}

(J. Phys. France 50 (1989) 485)

In equation (21) one should read :

$$
\Lambda(\hat{t})=\left(1-\frac{c^{4}}{8 \sqrt{\hat{t}}}\right)+\frac{1}{2} c^{2}\left(\frac{c^{4}}{16 \hat{t}}-\frac{1}{\sqrt{\hat{t}}}+y_{\mathrm{F}}\right)^{1 / 2}
$$

